\title{
LITERATUR REVIEW: PENERAPAN BATUK EFEKTIF DAN FISIOTERAPI DADA UNTUK MENGATASI KETIDAKEFEKTIFAN BERSIHAN JALAN NAFAS PADA KLIEN YANG MENGALAMI TUBERCULOSIS (TBC)
}

\author{
Wahyu Widodo ${ }^{1,}$ Siska Diyah Pusporatri, ${ }^{2}$ \\ Akademi Keperawatan Pemkab Purworejo \\ Purworejo, (0275)3140576 \\ Email:wahyumkepwidodo@gmail.com
}

\begin{abstract}
ABSTRAK
Latar Belakang : Tuberculosis (TB) merupakan suatu penyakit yang disebabkan oleh bakteri Mycobacterium Tuberculosis masuk kedalam saluran pernafasan dan menyerang paru-paru sehingga pada bagian alveolus terdapat bintil-bintil atau peradangan pada dinding alveolus akan mengecil. Prevalensi TB paru berdasarkan diagnose dokter menurut provinsi 2013-2018 Indonesia menduduki 0,4\% dari seluruh jumlah populasi. Tujuan : untuk mengetahui penerapan batuk efektif dan fisioterapi dada dalam mengurangi ketidakefektifan bersihan jalan nafas pada klien tuberculosis. Metode : penelitian yang digunakan dengan menganalisis artikel dan dilakukan penelusuran melalui google scholar dengan menggunakan kata kunci "fisioterapi dada dan batuk efektif", "fisioterapi dada dan batuk efektif"+ "tuberculosis", "penatalaksanaan batuk efektif dan fisioterapi dada"+ "tuberculosis", "pengaruh batuk efektif dan fisioterapi dada"+ "tuberculosis". Hasil : dari 5 jurnal didapatkan bahwa terjadi perubahan irama nafas, mampu mengeluarkan sekret, sesak nafas berkurang setelah dilakukan batuk efektif dan fisioterapi dada. Kesimpulan : penerapan batuk efektif dan fisioterapi dada pada pasien TB yang mengalami ketidakefektifan bersihan jalan nafas mampu mengurangi sesak nafas dan mengeluarkan spuntum dan disarankan klien bisa untuk melakukan batuk efektif dan fisioterapi dada secara mandiri.
\end{abstract}

Kata Kunci : Asuhan Keperawatan, Tuberculosis, Ketidakefektifan Bersihan Jalan Nafas

\section{ABSTRACT}

Background : Tuberculosis is a disease caused by mycobacterium tuberculosis that get into respiratory tract and the lungs so that there was rash in alveoli or inflammation, the alveolar walls then will shrink. The prevalence of tuberculosis based on doctor diagnosis by provience 2013-2018 indonesia occupies $0,4 \%$ of the population. Purpose : The Purpose of writing literature review is to conduct research on clients who have tuberculosis with ineffective airway clearance. Method : The method research used by analyzing articles and searching through google scholar by using the keywords "chest physiotherapy and effective cough", "chest physiotherapy and effective cough"+"tuberculosis", "management of effective cough and chest physiotherapy" + "tuberculosis", "effect of effective cough and chest physiotherapy" + "tuberculosis". Results : The result from 5 journals found that there was a change in breathing rhythm, are able t secrete, shorthnes of breath decreases after effective coughing and chest physiotherapy. Conclusions : The conclutions application of effective cough and chest physiotherapy in tuberculosis patients who experience ineffective airway clearance can reduce shortness breath and spuntum and it is recommended that client can do effective chough and chest physiotherapy independently

Keywords : Nursing care, Tuberculosis, Ineffectiveness of the airway clearance 


\section{Latar Belakang}

Tuberkulosis Paru merupakan suatu penyakit infeksi yang disebabkan oleh mycobacterium tuberculosis yakni kuman aerob yang dapat hidup terutama pada paru atau organ tubuh lainnya yang mempunyai tekanan parsial oksigen yang tinggi. Kuman ini mempunyai kandungan lemak yang tinggi pada membrane selnya sehingga menyebabkan bakteri ini tahan terhadap asam dan tidak tahan terhadap sinar ultraviolet, karena itu penularannya terutama pada malam hari (Rabb, 2010).

Tuberkulosis paru adalah terjadinya penumpukan atau akumulasi secret pada saluran pernafasan bagian atas. Hal ini terjadi karena bakteri merusak daerah parenkim paru menyebabkan terjadinya reaksi inflamasi yaitu produksi secret yang berlebihan dapat menyebabkan gangguan pernafasan karena obstruksi jalan nafas sehingga timbulah masalah ketidakefektifan bersihan jalan nafas (Andra \& Yessie, 2013).

Menurut World Health Organitazion (WHO) Indonesia menempati urutan ketiga jumlah kasus tuberculosis setelah India dan Cina dengan jumlah sebesar 700 ribu kasus. Angka kematian masih sama dengan tahun 2011 sebesar 27 per 100.000 penduduk, tetapi angka insidennya turun menjadi 185 per 100.000 penduduk di tahun 2012. Di Indonesia jumlah prevalensi TB paru berdasarkan diagnose dokter menurut provinsi 2013-2018 berjumlah 0,4\% dari seluruh jumlah populasi, sedangkan di Jawa Tengah jumlah 0,4\%. (Riskesdas, 2018).
Penyakit tuberculosis merupakan penyaki menular yang disebabkan mycrobacterium tuberculosis yang menyerang paru-paru melalui saluran pernafasan, saluran pencernaan dan luka terbuka pada kulit, selanjutnya dapat terjadi proses peradangan (inflamasi) di alveoli yang nantinya akan menimbulkan penumpukan spuntum yang berlebih dan menimbulkan masalah ketidakefektifan bersihan jalan nafas (Nurarif \& Kusuma, 2015)

Dampak yang terjadi jika ketidakefektifan bersihan jalan nafas tidak segera diatasi, dapat menimbulkan kekurangan oksigen dalam sel tubuh .Sel tubuh yang kekurangan oksigen akan sulit berkonsentrasi karena metabolism terganggu akibat kurangnya suplai oksigen dalam darah. Otak merupakan organ yang sangat sensitive terhadap kekurangan oksigen, apabila kekurangan oksigen lebih dari lima menit dapat terjadi kerusakan sel otak permanen.

Rencana keperawatan yang dilakukan yaitu manajemen jalan nafas, meliputi fisioterapi dada, motivasi klien untuk mengeluarkan secret (batuk efektif). Terapi yang diberikan itu mengajarkan batuk efektif. Menurut Perry \& Potter dalam Alie (2015), Batuk efektif adalah suatu metode batuk dengan benar, dimana klien menghemat energy sehingga tidak mudah lelah dan dapat mengeluarkan dahak secara maksimal. Menurut marni (2016), batuk efektif merupakan upaya untuk mengeluarkan dahak agar paru-paru tetap bersih. Cara melakukan batuk efektif menurut Pranowo (2016) adalah yang pertama yaitu 
menganjurkan pasien untuk minum hangat, kemudian tarik nafas dalam (lakukan sebanyak 3 kali) setelah tarik nafas yang ketiga, menganjurkan pasien untuk batuk yang kuat. Setelah dilakukan batuk efektif dahak bisa keluar meskipun sedikit.

Selanjutnya selain batuk efektif dapat dilakukan terapi nonfarmakologi yaitu melakukan fisioterapi dada. Fisioterapi dada adalah suatu tindakan untuk membersihkan jalan nafas dan spuntum, mencegah akumulasi spuntum, dan memperbaiki saluran pernafasan (Sari, 2016). Prosedur dari fisioterapi dada adalah auskultasi suara nafas pasien untuk mengetahui letak penumpukan spuntum sehingga memudahkan ketika mengatur posisi pasien.

\section{Metode}

Metode penelitian yang digunakan pada penelitian ini adalah literature review, yaitu mengumpulkan dan menganalisis jurnal penelitian mengenai penerapan batuk efektif dan fisioterapi dada. Artikel yang dipilih adalah artikel yang dipublikasikan sejak tahun 2015 sampai 2020 yang dapat diakses full teks dalam format pdf dan bahasa Indonesia.

\section{Hasil}

Hasil analis dan sintesis dari 5 artikel menunjukkan bahwa bahwa batuk efektif dan fisioterapi dada dapat digunakan untuk mengeluarkan spuntum dan mengurangi sesak nafas pada masalah ketidakefektifan bersihan jalan nafas yang dialami oleh klien tuberculosis

\section{Tabel 1.1 Hasil Analisa dan Sintesa Jurnal}

\begin{tabular}{|c|c|c|c|c|}
\hline No & Judul & Metode penelitian & $\begin{array}{c}\text { Subjek } \\
\text { penelitian }\end{array}$ & Hasil \\
\hline 1. & $\begin{array}{l}\text { Fisioterapi dada dan } \\
\text { batuk efektif sebagai } \\
\text { penatalaksanaan } \\
\text { besihan jalan nafas pada } \\
\text { pasien TB paru di } \\
\text { RSUD kota kendari } \\
\text { (Rusna Tahir, Dhea Sry } \\
\text { Ayu Imalia S, Siti } \\
\text { Muhsinah 2019) }\end{array}$ & $\begin{array}{l}\text { Metode penelitian yang } \\
\text { adalah dekriptif dengan } \\
\text { pendekatan observasional } \\
\text { melalui studi kasus untuk } \\
\text { memperoleh gambaran } \\
\text { penerapan fisioterapi } \\
\text { dada dan batuk efektif } \\
\text { pada pasien TB paru }\end{array}$ & $\begin{array}{l}\text { Subjek penelitian } \\
\text { ini berfokus pada } \\
\text { satu pasien yang } \\
\text { menjalani } \\
\text { peawatan }\end{array}$ & $\begin{array}{l}\text { Hasil dari penelitian ini diperoleh } \\
\text { penerapan fiioterapi dada dan batuk } \\
\text { efektif dilakukan } 3 \text { hari dengan } \\
\text { frekueni latihan 2x dan setelah } \\
\text { dilakukan fisioterapi dada dan batuk } \\
\text { efekif terjadi perubahan irama nafas } \\
\text { dari tidak teratur menjadi teratur. }\end{array}$ \\
\hline 2. & $\begin{array}{l}\text { Penerapan batuk efektif } \\
\text { mengatasi } \\
\text { ketidakefektifan } \\
\text { bersihan jalan nafas } \\
\text { pada Tn.M dengan } \\
\text { tuberculosis } r \text { (Siti } \\
\text { Fatimah, Syamsudin } \\
\text { 2019) }\end{array}$ & $\begin{array}{l}\text { Metode peneltian ini } \\
\text { menggunakan metode } \\
\text { untuk menyelidiki dan } \\
\text { mempelajari r suatu } \\
\text { kejadian mengenai } \\
\text { keadaan seseorang yang } \\
\text { dilakukan secara } \\
\text { integrative, komperhensif }\end{array}$ & $\begin{array}{l}\text { Subjek penelitian } \\
\text { ini diterapkan } \\
\text { pada satu pasien } \\
\text { tb. }\end{array}$ & $\begin{array}{l}\text { Hasil dari penelitian ini adalah } \\
\text { didapatkan hasil suara ronkhi masih } \\
\text { terdengar tetapi hanya disebelah } \\
\text { kanan saja dan sudah berkurang dari } \\
\text { hari sebelumnya dan mampu } \\
\text { mengeluarkan sekret. }\end{array}$ \\
\hline 3 & $\begin{array}{l}\text { Asuhan keperawatan } \\
\text { ketidakefektifan } \\
\text { bersihan jalan nafas } \\
\text { behubungan dengan } \\
\text { akumulasi secret pada } \\
\text { pasien tuberculosis di }\end{array}$ & $\begin{array}{l}\text { Metode penelitian ini } \\
\text { menggunakan } \\
\text { pengumpulan data dalam } \\
\text { studi kasus ini adalah } \\
\text { metode wawancara dan } \\
\text { metode observasi melalui }\end{array}$ & $\begin{array}{l}\text { Subjek penelitian } \\
\text { ini menggunakan } \\
2 \text { pasien yang } \\
\text { mengalami } \\
\text { tuberculosis }\end{array}$ & $\begin{array}{l}\text { Klien } 1 \text { seluruh kriteria hasil berhasil } \\
\text { terlampaui dalam batas waktu yang } \\
\text { telah ditentukan yaitu selama } 3 \times 24 \\
\text { jam sehingga masalah } \\
\text { ketidakefektifan bersihan jalan nafas } \\
\text { dapat teratasi sedangkan klien } 2\end{array}$ \\
\hline
\end{tabular}




\begin{tabular}{|c|c|c|c|c|}
\hline No & Judul & Metode penelitian & $\begin{array}{c}\text { Subjek } \\
\text { penelitian }\end{array}$ & Hasil \\
\hline & $\begin{array}{l}\text { RSI sakinah mojokerto. } \\
\text { (Arum Yulaeni,Ima } \\
\text { Rahmawati, Agus } \\
\text { Haryanto 2018) }\end{array}$ & $\begin{array}{l}\text { pemeriksaan fisik dengan } \\
\text { menggunakan stetoskop, } \\
\text { thermoter, serta dari hasil } \\
\text { pemeriksaan } \\
\text { laboratorium. }\end{array}$ & & $\begin{array}{l}\text { seluruh kriteria hasil belum } \\
\text { terlampaui dalam batas waktu yang } \\
\text { ditentukan } \\
\text { keperawingga masalah } \\
\text { bersihan jalan nafas hanya teratasi } \\
\text { sebagian. }\end{array}$ \\
\hline 4. & $\begin{array}{l}\text { Penerapan batuk efektif } \\
\text { dan fisioterapi dada } \\
\text { pada pasien tb paru } \\
\text { dengan } \\
\text { ketidakefektifan } \\
\text { bersihan jalan nafas di } \\
\text { RSUD koja Jakarta } \\
\text { utara (Egeria Dorina } \\
\text { Sitorus, dkk 2018) }\end{array}$ & $\begin{array}{l}\text { Metode penelitian yang } \\
\text { digunakan pendekatan } \\
\text { studi kasus dengan } \\
\text { wawancara terstrukur, } \\
\text { studi dokumen, dan } \\
\text { observasi menggunakan } \\
\text { instrument yang sudah } \\
\text { ditetapkan. }\end{array}$ & $\begin{array}{l}\text { Subjek penelitian } \\
\text { ini menggunakan } \\
2 \text { pasien tb yang } \\
\text { mengalami } \\
\text { ketidakefektifan } \\
\text { bersihan jalan } \\
\text { nafas. }\end{array}$ & $\begin{array}{l}\text { Hasil penelitian ini menunjukkan } \\
\text { bahwa studi kasus adanya } \\
\text { peningkatan pengeluaran sekret pada } \\
\text { klien dengan tb paru yang mendapat } \\
\text { tindakan fisioterapi dada dan batuk } \\
\text { efektif sehingga klien mampu } \\
\text { mempertahankan jalan nafas yang } \\
\text { efektif }\end{array}$ \\
\hline 5. & $\begin{array}{l}\text { Pengelolaan } \\
\text { ketidakefektifan } \\
\text { bersihan jalan nafas } \\
\text { pada Tn.M dengan } \\
\text { tuberculosis paru di } \\
\text { ruang dahlia RSUD } \\
\text { ungaran. (Antoninho } \\
\text { Coni Santana, Ummu } \\
\text { Muntamah 2019) }\end{array}$ & $\begin{array}{l}\text { Metode penelitian ini } \\
\text { menggunakan metode } \\
\text { pendekatan metodologi } \\
\text { keperawatan meliputi } \\
\text { diagnosa keperawatan, } \\
\text { tindakan keperawatan, } \\
\text { dan ranaluasi } \\
\text { keperawatan. }\end{array}$ & $\begin{array}{l}\text { Subjek penelitian } \\
\text { ini menggunakan } \\
\text { pasien } \\
\text { tuberculosis yang } \\
\text { dilakukan selama } \\
2 \text { hari }\end{array}$ & $\begin{array}{l}\text { Hasil setelah dilakukan pengelolaan } \\
\text { didapatkan masalah ketidakefektifan } \\
\text { bersihan jalan nafas teratasi sebagian, } \\
\text { klien dapat mengeluarkan dahak dn } \\
\text { sesak nafas berkurang. }\end{array}$ \\
\hline
\end{tabular}

\section{Pembahasan}

Tindakan yang pertama yaitu mengajarkan batuk efektif. Menurut Perry \& Potter dalam Alie (2015), Batuk efektif adalah suatu metode batuk dengan benar, dimana klien menghemat energi sehingga tidak mudah lelah dan dapat mengeluarkan dahak secara maksimal. Tindakan keperawatan yang kedua yaitu melakukan fisioterapi dada. Fisioterapi dada adalah suatu tindakan untuk membersihkan jalan nafas dan spuntum, mencegah akumulasi spuntum, dan memperbaiki saluran pernafasan (Sari, 2016).

Pada penelitian ke 5 artikel di atas menunjukkan bahwa teknik batuk efektif dan fisioterapi dada untuk mengatasi ketidakefektifan bersihan jalan nafas pada klien tuberculosis.
Sedangkan untuk perbedaan yang terjadi pada ke 5 ju artikel tersebut memiliki perbedaan masing-masing dengan hasil yang berbeda.

Pada artikel yang pertama terjadi perubahan irama nafas dari tidak teratur menjadi teratur pada satu pasien yang menjalani perawatan dimana penelitian tersebut menggunakan metode deskriftif dengan pendekatan observasional melalui studi kasus.

Pada artikel kedua terjadi perbedaan yang signifikan sebelum dan sesudah dilakukan tindakan batuk efektif dan fisioterapi dada dimana penelitian ini peneliti menggunakan 2 kelompok yaitu kelompok fisioterapi dada dan kelompok batuk efektif, dimana peneliti menggunakan metode rancangan Quasy eksperiment, jumlah sample 30 orang tiap kelompok cara pengambilan sample consecutive 
sampling dan menggunakan uji t-independen dan t-dependen.

Pada artikel ketiga menggunakan metode penelitian ini menggunakan pengumpulan data dalam studi kasus ini adalah metode wawancara dan metode observasi melalui pemeriksaan fisik dengan menggunakan stetoskop, thermometer, serta dari hasil pemeriksaan laboratorium dimana peneliti menggunakan 2 klien yang mengalami tuberculosis dan terdapat perbedaan antara 2 klien dimana klien 1 masalah keperawatan terlampaui dalam waktu $3 \times 24$ jam dan klien 2 masalah keperawatan hanya teratasi sebagian.

Pada artikel keempat terdapat peningkatan pengeluaran sekret pada klien dengan TB paru yang mendapat tindakan fisioterapi dada dan batuk efektif sehingga klien mampu mempertahankan jalan nafas yang efektif pada 2 pasien.

Pada artikel kelima, menggunakan metode pendekatan metodologi keperawatan meliputi pengkajian, diagnose keperawatan, tindakan keperawatan, dan evaluasi keperawatan dengan menggunakan 1 pasien tuberculosis dimana masalah ketidakefektifan bersihan jalan nafas teratasi sebagian, klien dapat mengeluarkan dahak dan sesak nafas berkurang.

Pandangan yang diberikan kepada klien yaitu sesuai dengan konsep yang menyatakan latihan batuk efektif dan fisioterapi dada merupakan suatu bentuk untuk membebaskan jalan nafas yang dinilai masih cukup efektif untuk mengatasi ketidakefektifan bersihan jalan nafas tidak efektif pada klien yang mengalami tuberculosis.

\section{Kesimpulan}

Berdasarkan penjelasan diatas yang terdiri dari 5 artikel ilmiah yang telah dilakukan review maka telah terbukti bahwa dari penelitian batuk efektif dan fisioterapi dada dapat digunakan sebagai cara untuk mengatasi ketidakefektifan bersihan jalan nafas yang dialami oleh klien tuberculosis. Dalam hal ini penulis mengucapkan terima kasih kepada Direktur Akper Pemkab Purworejo, dosen pembimbing dan teman-teman sekalian yang telah memberikan dukungan moril maupun materil dalam penyelesaian literature review.

\section{Ucapan Terima Kasih}

Penulis mengucapkan terima kasih kepada direktur akper pemkab purwoejo dan ketua lembaga penelitian dan pengabdian kepada masyarakat yang telah memfasilitasi jalannya penelitian hingga pubilkasi.

\section{Daftar Pustaka}

Alie, Yulianti dan Rodiyah.2015. Pengaruh Batuk Efektif Terhadap Pengeluaran Spuntum pada Pasien Tuberculosis di Peterangan Kabupaten Jombang. Jombang. Jurnal Metabolisme, 2(3), 1521.https://doi.org/10.1111/jce.12992.This

Andra, SW \& Yessi, MP 2013, Keperawatan Medical Bedah, Yogyakarta: Nura Medika

Antoninho Coni Santana, Ummu Muntamah 2019) Pengelolaan ketidakefektifan bersihan jalan nafas pada Tn.M dengan 
tuberculosis paru di ruang dahlia RSUD ungaran.

Ardiansyah, M (2012). Medical Bedah. Yogyakarta : Diva Press

Hidayat, Aziz Alimul A. 2012. Pengantar Kebutuhan Dasar Manusia Aplikasi Konsep dan Proses Keperawatan Buku 2. Jakarta : Salemba Medika

Nurarif \& Kusuma 2016. Asuhan Keperawatan Praktis Berdasarkan Penerapan Diagnosa NANDA NIC NOC Dalam Berbagai Kasus. Jogjakarta: Media Action

Rab, Tabani. (2010). Ilmu Penyakit Paru. Jakarta: Trans Info Media

Riskesdas. (2018). Riset Kesehatan Dasar Republik Indonesia Tahun 2018.

Santana, A. C., \& Muntamah, U. (2019). Pengelolaan Ketidakefektifan Bersihan Jalan Napas pada Tn. $M$ dengan Tuberculosis Paru di Ruang Dahlia RSUD Ungaran.

Setyawati, D., Sukraeny, N., Sciences, H., Sciences, H., \& Sciences, H. (2018). Health Notions, Volume 2 Number 12 ( December 2018) Cold Compress on Vertebra ( Cervical) on The Pain Scale of Postoperative Patients 1231 | Publisher:
Humanistic Network for Science and Technology Health Notions, Volume 2 Number 12 ( December 2018 ). 2(12), 1231-1233.

Siti Fatimah, S. (2019). Penerapan teknik batuk efektif mengatasi ketidakefektifan bersihan jalan napas pada Tn. $m$ dengan tuberkulosis. Jurnal Keperawatan Karya Bhakti, 5(1), 26-30.

Sitorus, E. D., Lubis, R. M., \& Kristiani, E. (2018). Penerapan Batuk Efektif dan Fisioterapi Dada pada TB Paru yang Mengalami Ketidakefektifan Bersihan Jalan Napas Di RSUD Koja Jakarta Utara. Jurnal Kesehatan, 4(November 2014), 3741.

Tahir, R., Sry Ayu Imalia, D., \& Muhsinah, S. (2019). Fisioterapi Dada dan Batuk Efektif sebagai Penatalaksanaan Ketidakefektifan Bersihan Jalan Nafas pada Pasien TB Paru di RSUD Kota Kendari. Health Information : Jurnal Penelitian, 11(1), 2025. https://doi.org/10.36990/hijp.v11i1.87

Sari, D. P. (2016). Upaya Mempertahankan Kebersihan Jalan Napas Dengan Fisioterapi Dada Pada Anak Pneumonia. Electronic Theses and Dissertations Universitas Muhammadiyah Surakarta. http://eprints.ums.ac.id/id/eprint/44483

Yulaeni Arum 2018. Asuhan Keperawatan Ketidakefektifan Bersihan Jalan Nafas Berhubungan Dengan Akumulasi Sekret Pada Pasien TB Paru, RSI Sakinah Mojokerto. 